\title{
Originals
}

\section{Long-term follow-up of patients who underwent yttrium-90 pituitary implantation for treatment of proliferative diabetic retinopathy}

\author{
P. S. Sharp, T.J. Fallon, O.J. Brazier, L. Sandler, G. F. Joplin and E. M. Kohner \\ Department of Medicine, The Royal Postgraduate Medical School, London, UK
}

\begin{abstract}
Summary. Between 1960 and 1976117 patients underwent pituitary implantation with yttrium-90 $\left({ }^{90} \mathrm{Y}\right)$ for treatment of proliferative retinopathy at the Hammersmith Hospital, London. Mean age at operation was $35 \pm 11$ years (mean $\pm \mathrm{SD}$ ), and mean duration of diabetes $18.6 \pm 10.0$ years. Mean insulin dosage prior to implant was $67.2 \pm 24$ units, falling to $30.4 \pm 14.9$ units post-implant. Thirty-two per cent of patients are still living, $60 \%$ are deceased and $8 \%$ are lost to followup. The 5-year survival rate was $82 \%$. Of the causes of death, $21 \%$ died of infection, adrenal insufficiency or hypoglycaemia, $12 \%$ of renal failure, and $47 \%$ of myocardial or cerebral vascular disease. Ophthalmological follow-up was carried out on the 100 patients operated on between 1965 and 1976. The mean age of this group at implant was $35 \pm 10.5$ years, and mean duration of diabetes $17.2 \pm 8.7$ years. Visual acuity in the better eye at operation was $6 / 12$ or better in $84 \%$ of
\end{abstract}

patients, and this percentage remained similar at the time of the 5 and 10 year follow-up. Blindness (6/60 or worse) in both eyes was present in $12 \%$ of patients at the time of 5 and 10 year assessments. By 5 years new vessels on the disc had improved from a mean grading of $2.7 \pm 1.6$ to $0.8 \pm 1.2(p<$ 0.001 ), and by 10 years there was no disc neovascularisation in any eye. There was a similar improvement in the grading of hard exudates, microaneurysms and haemorrhages, but there was an increase in fibrous retinitis proliferans. It is concluded that pituitary ablation was an effective method of treating proliferative retinopathy, and may have had a beneficial effect on other microvascular complications.

Key words: Pituitary ablation, yttrium-90, renal function, survival, proliferative retinopathy.

fibrous retinitis proliferans and retinal detachment were initially treated by this means. Further, the radiation dose at the gland periphery was varied from $50,000 \mathrm{rad}$ to $300,000 \mathrm{rad}$ in order to ascertain the optimum level. By 1965 it was established that $150,000 \mathrm{rad}$ achieved complete ablation in the majority of patients, and side effects such as diabetes insipidus and CSF rhinorrhoea were of acceptably low frequency.

Pituitary implantation with ${ }^{90} \mathrm{Y}$ for proliferative retinopathy was carried out in a large series of patients at the Hammersmith Hospital between 1960 and 1976, with use of the procedure for this indication being discontinued with the advent of photocoagulation. The short-term results on retinal features and visual acuity have been reported in various groups of these patients [4-11]. We report here on the medical aspects of longterm follow-up of all patients operated on between 1960 and 1976; the ophthalmological outcome in a group of these patients describes only those operated on after 1965, when the retinal indications for pituitary implantation were known. 


\section{Subjects and methods}

The medical selection criteria for consideration of pituitary ablation for diabetic retinopathy at the Hammersmith Hospital were: (1) good general health (2) blood urea below $12.5 \mathrm{mmol} / 1$ (3) ability to manage diabetes under difficult circumstances. One hundred seventeen patients who underwent pituitary implantation with ${ }^{90} \mathrm{Y}$ for diabetic retinopathy at the Hammersmith Hospital between 1960 and 1976 have been followed. This number does not include the one patient who died immediately post-operatively. The mean age of the patients was $35 \pm 11$ years (mean $\pm S D$ ), with a range of $16-62$ years. The mean duration of diabetes prior to implantation was $18.6 \pm$ 10.0 years. All but one had proliferative retinopathy. Before operation, 13 patients were being treated with diet alone or diet plus oral hypoglycaemic agents; the remainder were on insulin therapy. After implantation, all but one were treated with insulin. The irradiation dose was $300 \mathrm{krad}$ or more in $54 \%$ of subjects, $150 \mathrm{krad}$ in $40 \%$ and $50 \mathrm{krad}$ in $6 \%$. Of the total, $22 \%$ had more than one implant in an attempt to achieve complete ablation.

Patients attended the Hammersmith Hospital for review at least once a year. If this was not possible due to difficulties with traveling, a medical report was obtained from the patient's local diabetic clinic. Where neither of these possibilities was available, the patient was considered to be lost to follow-up. Cause of death was taken from the death certificate. Where possible, clinical details were also obtained from the attending physician at the time of death. Results of post-mortem examination were taken into consideration when available.

Assessment of pituitary function in the early patients consisted of an insulin tolerance test with measurement of growth hormone (GH), metyrapone test with measurement of 17-oxogenic steroids, $48 \mathrm{~h}{ }^{131}$ I neck uptake and steroid withdrawal with assessment of symptoms. These tests have been changed and superseded over the years to the present methods of pituitary function testing outlined below. For this report, assessment of pituitary function at any time depends on the tests then available.

Patients for re-assessment of pituitary function underwent an insulin tolerance test, where there were no contraindications, with simultaneous administration of luteinising hormone/follicle stimulating hormone releasing hormone (LH/FSH-RH) and thyrotrophin releasing hormone (TRH) [12]. In view of the fact that the patients were diabetic and hypopituitary, the dose of insulin given was 0.15 units $/ \mathrm{kg}$ body weight (Actrapid, Novo). If there was no significant fall in the blood glucose within $30 \mathrm{~min}$, a further dose was given as considered appropriate. In all subjects the plasma glucose fell below $2.5 \mathrm{mmol} / \mathrm{l}$, and symptomatic hypoglycaemia was obtained. Blood samples were taken at 30 min intervals for measurement of $\mathrm{GH}$, cortisol and prolactin; these measurements continued for at least $60 \mathrm{~min}$ after symptomatic hypoglycaemia was achieved. Patients in whom insulin tolerance testing was contraindicated were given, in addition to LH/FSH-RH and TRH as above, an intravenous bolus of $100 \mu \mathrm{g}$ growth hormone releasing factor (GRF, Peninsula Laboratories, Calif., USA) with measurement of serum GH at $15 \mathrm{~min}$ intervals for $90 \mathrm{~min}$. The maximum serum $\mathrm{GH}$ was taken as a measure of the patient's somatotroph function. Glycosylated haemoglobin A1 was measured by ion exchange chromatography (Bio Rad Kit).

One hundred patients who underwent ${ }^{90} \mathrm{Y}$ pituitary implantation for proliferative diabetic retinopathy between 1965 and 1976 were included in the ophthalmological follow-up. Patients were carefully assessed prior to being offered pituitary ablation. They were considered eligible for this treatment if, in addition to the medical criteria quoted above, they had at least one 'treatable' eye defined as visual acuity of $6 / 24$ or better, the macula not threatened by fibrous retinitis proliferans (RP) and/or detachment, and RP on the disc not exceeding grade 3 out of 5 on the Hammersmith grading system [13]. If complete ablation was not achieved with one operation, and an eye remained treatable, a second operation was offered. Twenty-three patients had two pituitary implants.

Patients admitted to the study were assessed at regular intervals, and once a year underwent a full ophthalmic examination including measurement of best corrected visual acuity and intraocular pressure. Anterior segment examination and retinal evaluation including colour photography of the fundus and fluorescein angiography were also performed. Colour photographs were assessed using the Hammersmith system, which separately grades microaneurysms and haemorrhages (MA), new vessels elsewhere (NVE), retinitis proliferans (RP) and hard exudates (HE) on a numerical system between 0 (absent) and 5 (most severe), based on comparison with standard photographs [13]. New vessels arising from the disc (NVD) were graded according to the method of Kohner et al. [14] by assessing the number of quadrants of the optic disc crossed by the new vessels and the distance the vessels extend beyond the disc margin, again assigning a value of 0 to 5 . Photocoagulation had been carried out on 15 patients before they entered the study, and pituitary ablation was performed in these cases because of failure of response.

Ophthalmic records of each patient were recently reviewed. Retinopathy grading and visual acuity immediately prior to implant ('initial') and at 1, 3, 5, 10 and 15 years post-implant, had been recorded and were available for consideration. Original photographs were examined in $15 \%$ to verify the original gradings, which were done by different observers over the years. In the sample tested, no changes in grading had to be made. For the purposes of this study 'blindness' is defined as visual acuity of $6 / 60$ or worse. For the purposes of data analysis, time of entry into the study in the 23 patients who had a second implant was immediately prior to the first operation. Visual acuity results were converted from Snellen-chart values to numerical scoring to facilitate statistical analysis (Table 1).

\section{Statistical analysis}

Data are quoted as mean $\pm S D$ throughout. The significance of differences between groups was assessed using a paired Student's t-test.

\section{Results}

\section{Medical follow-up}

Of the 117 patients, 108 (92\%) have been successfully followed (84\% at the Hammersmith Hospital) and 9 $(8 \%)$ lost to follow-up (8 of whom were resident abroad). All patients were followed for at least 6 months post-implant; the longest has now been followed for 21 years. The mean follow-up period is $10.0 \pm 4.9$ years (i. e. time from implant to death or to the present time if still alive).

Pituitary function. Of the total number of patients, the mean insulin dose pre-implant was $62.7 \pm 24$ units, falling 6 months post-implant to $30.4 \pm 14.9$ units. On evidence available at the time, 90 patients $(77 \%)$ were thought to have complete pituitary ablation, $22(19 \%)$ to be partially ablated [which number includes all

Table 1. Numerical scoring of visual acuity

$\begin{array}{ll}6 / 6=1 & 6 / 60=7 \\ 6 / 9=2 & 3 / 60=8 \\ 6 / 12=3 & \text { CF }=9 \\ 6 / 18=4 & \text { HM }=10 \\ 6 / 24=5 & \text { PL }=11 \\ 6 / 36=6 & \text { NPL }=12\end{array}$

$\mathrm{CF}=$ counting fingers; $\mathrm{HM}=$ hand movements; $\mathrm{PL}=$ perception of light; NPL $=$ no perception of light 
Table 2. Pituitary function tests in 7 patients thought to have partial ablation on original assessment (maximum values during combined pituitary function testing)

\begin{tabular}{|c|c|c|c|c|c|c|c|}
\hline Patient & Sex & $\begin{array}{l}\text { Irradiation } \\
\text { dosage } \\
\text { (krad) }\end{array}$ & $\begin{array}{l}\text { Plasma } \\
\text { GH } \\
(\mathrm{mU} / 1)\end{array}$ & $\begin{array}{l}\text { Plasma } \\
\text { cortisol } \\
\text { (nmol/l) }\end{array}$ & $\begin{array}{l}\text { Thyrotrophin } \\
\text { (TSH) } \\
\text { (mU/1) }\end{array}$ & $\begin{array}{l}\text { Luteinising } \\
\text { hormone } \\
(\mathrm{U} / \mathrm{l})\end{array}$ & $\begin{array}{l}\text { Follicle } \\
\text { stimulating } \\
\text { hormone } \\
(\mathrm{U} / \mathrm{l})\end{array}$ \\
\hline JM-S & F & 50 & 11.0 & 660 & 13.5 & 19.4 & 8.0 \\
\hline $\mathrm{TH}$ & $\mathrm{M}$ & 150 & 4.2 & 305 & $<1$ & 1.8 & $<1$ \\
\hline PS & $\mathbf{F}$ & 50 & 2.6 & 750 & 9.3 & 17.0 & 16.6 \\
\hline $\mathrm{AJ}$ & $\mathbf{F}$ & 300 & 1.6 & 176 & $<1$ & 14.3 & 8.6 \\
\hline SB & $F$ & 300 & $<1$ & 526 & 2.9 & 7.5 & 4.5 \\
\hline $\mathrm{RC}$ & M & 300 & $<1$ & $<55$ & $<1$ & 1.2 & $<1$ \\
\hline DB & $\mathrm{F}$ & 300 & 1.7 & $<55$ & $<1$ & $<1$ & $<1$ \\
\hline Normal: & & & $>20$ & $>550$ & $>4.5$ & $>16$ & $>2$ \\
\hline
\end{tabular}

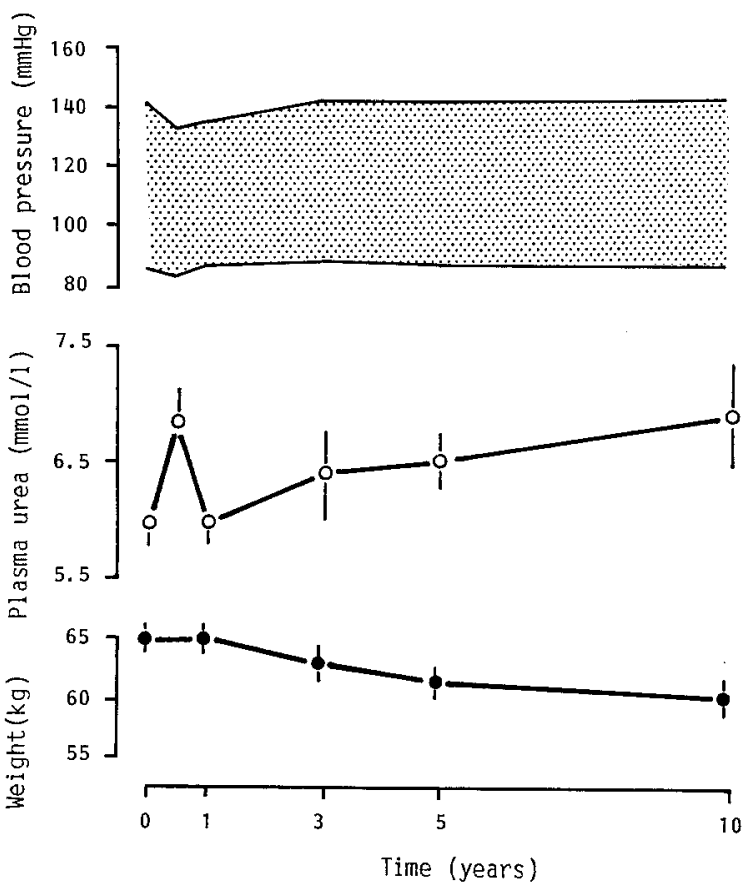

Fig. 1. Changes in blood pressure, plasma urea and body weight with time in all patients followed

7 patients who had the $50 \mathrm{krad}$ radiation dosage, 2 of whom are still surviving (Table 2)], leaving $5(4 \%)$ in whom insufficient evidence was available. Of the currently surviving 38 patients, 23 were admitted to hospital for reassessment of their pituitary function as above. This number included 7 of the 8 surviving patients who had been thought to have some residual pituitary function. Results from these 7 patients are shown in Table 2, where it is seen that one had no detectable pituitary function and the remainder had reduced reserve secretion. The other 16 patients who were tested and had been thought to be completely ablated were all confirmed to be so with no response to any of the stimulatory tests performed.

Replacement therapy. Of the 108 patients followed, $96 \%$ were taking replacement therapy with prednisone or hydrocortisone and thyroxine. Only $6(6 \%)$ have been replaced with fludrocortisone. The males were all taking intramuscular depot injections of testosterone at 3 to 6 weekly intervals. Amongst the females, it is difficult to persuade them of the need to take oestrogen replacement; at present, only one of the surviving women is doing so. No subject required any form of therapy for diabetes insipidus beyond 6 months postimplant.

Glycaemic control. Amongst the survivors, glycaemic control is difficult. The mean glycosylated $\mathrm{HbA}_{1}$ is $10.5 \pm 1.5 \%$ (normal range $5-8 \%$ ). The principal problem is hypoglycaemia, since in the majority of patients this is asymptomatic until it results in loss of consciousness. Many patients complain that addition of 1 unit of insulin to their daily dosage leads to troublesome hypoglycaemia, and all are advised not to take long-acting preparations of insulin in the evening to avoid nocturnal hypoglycaemia.

Morbidity. At the time of implantation, $8 \%$ of the patients had a history suggestive of autonomic neuropathy (impotence, diarrhoea, postural hypotension or gustatory sweating) and $8 \%$ had some electrocardiographic abnormality. During the follow-up period, a further $18 \%$ developed autonomic neuropathy and 34\% an abnormality on ECG. There was a tendency to lose weight post-implant. At the time of operation, the mean weight was $64.8 \pm 8.8 \mathrm{~kg}$, falling to $60.3 \pm 9.1$ at 10 years $(p<0.01)$ (Fig. 1$)$. There was a drop in blood pressure at 6 months, but only the drop in systolic pressure reached significance (from a mean value of $141 / 85$ to $133 / 83$, the fall in systolic pressure being significant at $p<0.02$ ) (Fig. 1).

Apart from the general problems associated with hypopituitarism, there have been a number of problems peculiar to these patients with diabetes. In one patient postural hypotension has been so severe that, despite treatment with mineralocorticoids, she has been confined to a wheelchair. Osteoporosis with bone fractures has been a problem in a number of cases, and in one patient non-union of a fractured shaft of femur 


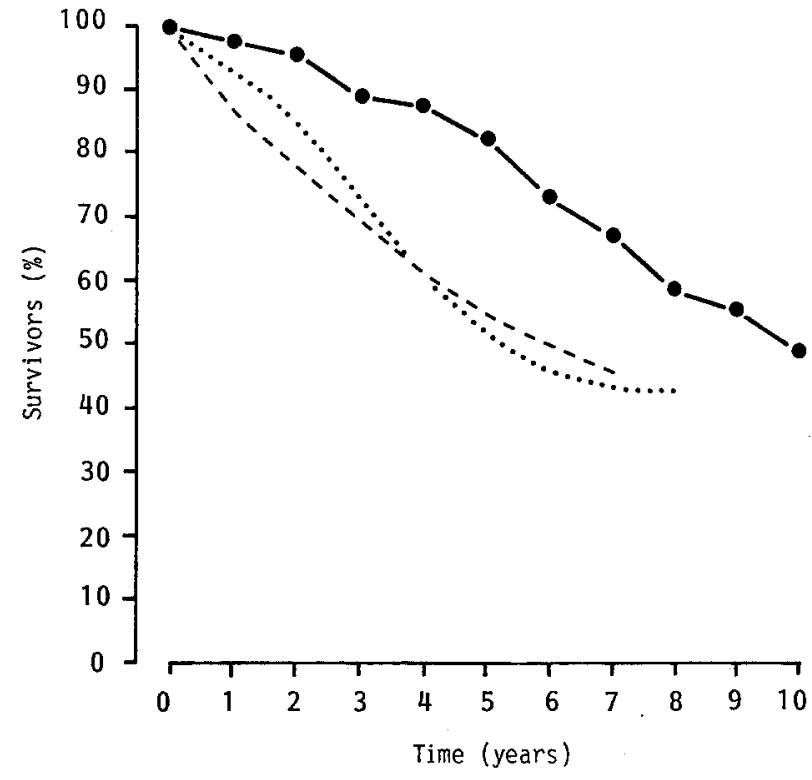

Fig. 2. Cumulative mortality for the 108 patients followed. Survival curves for the studies of Caird et al. [19] (dotted line) and Davis et al. [20] (dashed line) are shown for comparison

Table 3. Details of patients who died as a result of hypopituitarism

\begin{tabular}{|c|c|c|c|}
\hline Patient & $\begin{array}{l}\text { Age at } \\
\text { time of } \\
\text { death }\end{array}$ & $\begin{array}{l}\text { Years } \\
\text { post- } \\
\text { implant }\end{array}$ & Cause of death \\
\hline BB & 33 & 7 & Hypoglycaemia \\
\hline JB & 31 & 3 & Hypoglycaemia \\
\hline $\mathrm{AB}$ & 43 & 0.5 & $\begin{array}{l}\text { Meningitis, adrenocortical insuffi- } \\
\text { ciency }\end{array}$ \\
\hline DC & 33 & 7 & Hypoglycaemia \\
\hline $\mathrm{RC}$ & 47 & 2 & $\begin{array}{l}\text { Meningitis, adrenocortical insuffi- } \\
\text { ciency }\end{array}$ \\
\hline $\mathrm{BD}$ & 32 & 8 & $\begin{array}{l}\text { Asphyxia secondary to hypogly- } \\
\text { caemia }\end{array}$ \\
\hline TD & 38 & 8 & $\begin{array}{l}\text { Status epilepticus secondary to hy- } \\
\text { poglycaemia }\end{array}$ \\
\hline EG & 47 & 8 & Meningitis \\
\hline $\mathrm{DH}$ & 49 & 4 & $\begin{array}{l}\text { Pneumonia, adrenocortical insuffi- } \\
\text { ciency }\end{array}$ \\
\hline GK & 34 & 10 & Pneumonia, hypoglycaemia \\
\hline RN & 29 & 6 & Hypoglycaemia \\
\hline JP & 35 & 11 & Hypoglycaemia \\
\hline WR & 61 & 3 & Meningitis, hydrocephalus \\
\hline WR & 46 & 6 & $\begin{array}{l}\text { Pneumonia, adrenocortical insuffi- } \\
\text { ciency }\end{array}$ \\
\hline MW & 45 & 9 & Influenza \\
\hline
\end{tabular}

required pinning and 2 years to allow return to full mobility. Avascular necrosis of the femoral head on a dose of $5 \mathrm{mg}$ of prednisone has been reported in one case. Problems with hypopituitarism and diabetes are illustrated in the following 2 case histories, which are not atypical.

Patient GD, female with diabetes since the age of 14 years, was found to have 'florid' proliferative retinopathy in both eyes at the age of 31 years. Her visual acuity at the time was $6 / 9$ in the right eye, with repeated vitreous haemorrhages, and $6 / 60$ in the left eye due to retinal detachment. She was treated with a $300 \mathrm{krad}{ }^{90} \mathrm{Y}$ pituitary im- plant, and at 6 month assessment was thought to be completely ablated. Her daily insulin dosage had fallen from 40 to 24 units daily. She was on replacement therapy-with prednisone, thyroxine and oestrogens, although she discontinued the latter since she said they upset her diabetic control and made her feel unwell. Glycaemic control proved difficult, and she suffered from repeated hypoglycaemia. She was commenced on thrice daily Actrapid insulin, to a total of 20 units daily, and began monitoring her home blood glucose 4 times daily. Nevertheless, she is frequently found unconscious due to hypoglycaemia at home. She lives alone and is unmarried. Friends have frequently had to administer intramuscular glucagon, and she has had frequent hospital admissions with hypoglycaemia. Her renal function is normal, with a serum creatinine of $62 \mu \mathrm{mol} / 1$, and she has no proteinuria. She maintains $6 / 6$ vision in her right eye.

Patient MP, female with diabetes since the age of 2 years, was found to have bilateral proliferative retinopathy at the age of 27 years, and treated with a $150 \mathrm{krad}{ }^{90} \mathrm{Y}$ pituitary implant. On assessment at 6 months she was found to be completely ablated, and her daily insulin dosage had fallen from 60 to 30 units daily. She was on replacement therapy with prednisone and thyroxine. She developed pulmonary tuberculosis 3 years post-implant and was kept on prophylactic isoniazid in view of her steroid therapy. She had photocoagulation to the left eye in South Africa, and subsequently lost vision in that eye due to retinal detachment. When seen 12 years postimplant, age 39 years, her daily insulin dosage had dropped to 18 units daily, in spite of which she continued to have frequent hypoglycaemic attacks. Despite treatment with oestrogens and calciferol, she complained of back ache, and had sustained several fractures of ribs and fingers. On X-ray examination, she was found to have osteoporosis with collapse of T12 and wedge fractures of L3-4 in addition to 2 fractured ribs. When seen 16 years post-implant, her general health was poor. She was $5 \mathrm{~kg}$ less than her pre-implant weight. Her daily insulin dosage was down to 16 units daily, but she continued to suffer from repeated debilitating hypoglycaemic attacks, resulting in a fractured ankle on one occasion. She had never married and had no children. Her plasma creatinine was normal at $86 \mu \mathrm{mol} / 1$, and she had no proteinuria. She maintained $6 / 6$ vision in the right eye with no active retinopathy.

Mortality rate. Of the patients followed, $38(35 \%)$ are still alive at the time of writing and $70(65 \%)$ deceased. The 5 -year mortality was $18 \%$ and the 10 -year mortality $51 \%$ (Fig. 2).

Causes of death. Causes of death were confirmed by the attending physician or by postmortem examination in $49 \%$ of patients and taken from the death certificate in $51 \%$. Of the 70 patients who had died, $15(21 \%)$ died of the consequences of hypoglycaemia, infection or adrenal steroid deficiency. The mean survival time in this group was $6.2 \pm 3.1$ years. These patients are detailed in Table 3. Subjects BD and TD both suffered from epilepsy and, although treated with anticonvulsant agents, had grand mal seizures secondary to hypoglycaemia which resulted in their deaths. Eight patients $(12 \%)$ died of unequivocal renal failure (see below). The mean survival time of this group was $6.5 \pm 3.4$ years. Thirty-three patients $(47 \%)$ died of ischaemic heart disease or cerebral vascular disease, mean survival in this group being $8.2 \pm 3.5$ years. Fourteen patients $(20 \%)$ died of miscellaneous causes, including cancer, gastric haemorrhage and pancreatitis. This group also includes those in whom the death certificate states only bronchopneumonia, since this is often quoted as the cause of death where the exact cause 
Table 4. Patients who died with an elevated plasma urea

\begin{tabular}{lllllll}
\hline Patient & $\begin{array}{l}\text { Age at } \\
\text { implant } \\
\text { (years) }\end{array}$ & $\begin{array}{l}\text { Age at } \\
\text { death } \\
\text { (years) }\end{array}$ & $\begin{array}{l}\text { Urea at } \\
\text { implant } \\
\text { (mmol/1) }\end{array}$ & $\begin{array}{l}\text { Urea at } \\
\text { death } \\
\text { (mmol/1) }\end{array}$ & $\begin{array}{l}\text { Proteinuria } \\
\text { (Y/N) }\end{array}$ & Cause of death \\
\hline DB & 34 & 40 & 10.8 & 34.6 & Y & Myocarditis \\
MD & 48 & 60 & 5.8 & 13.0 & Not known & Cardiac failure, IHD \\
DF & 30 & 38 & 5.5 & Nonal failure \\
WF & 48 & 54 & 6.0 & 17.0 & Y & Cardiac failure, IHD \\
EH & 27 & 39 & 7.8 & 41.5 & Renal failure \\
MH & 30 & 33 & 8.8 & 30.6 & Renal failure \\
CJ & 23 & 28 & 7.6 & 31.3 & Y & Renal failure \\
AP & 42 & 52 & 10.7 & 44.7 & Y & Renal failure \\
SP & 20 & 23 & 6.5 & Not known & Renal failure \\
FS & 36 & 39 & 9.0 & Not known & Renal failure \\
RT & 28 & 35 & 7.2 & 45.0 & Y & Cardiac failure, IHD \\
AV & 55 & 64 & 7.1 & 17.2 & N & \\
\hline
\end{tabular}

MI myocardial infarction; IHD ischaemic heart disease

of death is unknown. Of all patients, both living and deceased, there had been no episodes of ketoacidosis.

Renal function. Assessment of renal function is difficult, since the only marker of renal function available consistently in all patients is plasma urea. While it is known that 16 patients (14\%) had proteinuria at the time of implant, the presence or absence of proteinuria during follow-up is not known in all patients. Table 4 gives details of all 12 patients who died with an elevated plasma urea $(>13 \mathrm{mmol} / \mathrm{l})$. One surviving patient has developed rapidly progressive renal failure 14 years post implant, and another has early renal failure, with a plasma creatinine of $154 \mu \mathrm{mol} / 1$ and poorly controlled hypertension. Thus, $13 \%$ of patients followed apparently developed some degree of renal failure. This figure is likely to be an overestimate, since on examination of the details in Table 4 some patients had medical conditions which could have contributed to an elevated plasma urea. Subjects MD, WF and AV had cardiac failure and were on diuretic therapy. Subject CV had a myocardial infarction following which her plasma urea was elevated. In addition, two patients had evidence of renal failure prior to implant with plasma urea greater than $10 \mathrm{mmol} / 1$ and proteinuria. Thus, only 8 patients $(7.4 \%)$ could truly be said to have developed renal failure post pituitary ablation. A plot of plasma urea against time (Fig. 1) shows a brief rise above basal $(6.1 \pm 1.6$ versus $7.3 \pm 2.6 p<0.05)$ within 6 months of operation followed by a swift return to normal and subsequent slow progressive rise. This is apparent even when the 12 patients who died with an elevated plasma urea are excluded.

\section{Ophthalmological follow-up}

Sixty-seven male and 33 female patients underwent pituitary ablation between 1965 and 1976. Mean age at entry was $35 \pm 10.5$ years (range 16-62 years) and mean duration of diabetes at entry was $17.2 \pm 8.7$ years
Table 5. Mean visual acuity of right eyes

\begin{tabular}{llll}
\hline Year & $\begin{array}{l}\text { Mean } \\
\text { grading }\end{array}$ & SD & $\begin{array}{l}\text { No. of } \\
\text { patients }\end{array}$ \\
\hline Right eyes & & & \\
Initial & 3.2 & 2.8 & 100 \\
One & 3.6 & 3.4 & $97^{\mathrm{a}}$ \\
Three & 4.3 & 3.8 & $83^{\mathrm{b}}$ \\
Five & 4.7 & 4.2 & $68^{\mathrm{b}}$ \\
Ten & 4.6 & 4.4 & $49^{\mathrm{b}}$ \\
Fifteen & 4.8 & 4.5 & $19^{\mathrm{a}}$ \\
Left eyes & & & \\
Initial & 4.1 & 3.4 & 100 \\
One & 4.5 & 3.6 & $97^{\mathrm{a}}$ \\
Three & 4.8 & 4.0 & $83^{\mathrm{b}}$ \\
Five & 4.6 & 4.2 & $68^{\mathrm{a}}$ \\
Ten & 4.7 & 4.4 & $49^{\mathrm{b}}$ \\
Fifteen & 5.1 & 4.7 & 19 \\
\hline
\end{tabular}

${ }^{\mathrm{a}} p<0.05 ;{ }^{\mathrm{b}} p<0.01$ comparing the same eye at initial and subsequent visits

(range 1-40 years). Fifteen patients who had previously had photocoagulation and were 'treatment failures' were included in the pituitary ablation series. At 10 years, a further 14 subjects had had photocoagulation.

Visual acuity. At the initial assessment there was a significant difference in the mean visual acuities between right and left eyes: right $3.2 \pm 2.8$, left $4.1 \pm 3.4, p<0.05$ (Table 5). Thirty-eight patients were blind in one eye, 14 in the right and 24 in the left. The cause of blindness was usually vitreous haemorrhage or RP causing traction detachment.

Sixty-eight patients were assessed at the five-year follow-up. Mean visual acuity had deteriorated to $4.7 \pm 4.2$ in the right eye $(p<0.001)$ and $4.6 \pm 4.2$ in the left eye $(p<0.02)$. At this stage eight patients were blind in both eyes, secondary to RP/detachment, vitreous haemorrhage or rubeotic glaucoma. Forty-nine patients were analysed at the 10-year follow-up. Com- 
Table 6. Grading of better eye from initial to the 15-year visit

\begin{tabular}{|c|c|c|c|c|c|c|c|c|c|c|c|c|c|}
\hline & $6 / 6$ & $6 / 9$ & $6 / 12$ & $6 / 18$ & $6 / 24$ & $6 / 36$ & $6 / 60$ & $3 / 60$ & $\mathrm{CF}$ & $\mathrm{HM}$ & $\mathrm{PL}$ & NPL & Total \\
\hline One & 54 & 21 & 8 & 5 & 2 & 4 & 1 & 0 & 1 & 1 & 0 & 0 & 97 \\
\hline Five & 38 & 14 & 3 & 3 & 1 & 1 & 2 & 0 & 1 & 2 & 1 & 2 & 68 \\
\hline Ten & 33 & 3 & 3 & 1 & 1 & 2 & 0 & 0 & 1 & 1 & 3 & 1 & 49 \\
\hline Fifteen & 12 & 2 & 0 & 1 & 0 & 0 & 2 & 0 & 0 & 0 & 0 & 2 & 19 \\
\hline
\end{tabular}

$\mathrm{CF}=$ counting fingers $; \mathrm{HM}=$ hand movements $; \mathrm{PL}=$ perception of light; $\mathrm{NPL}=$ no perception of light

pared with the 5-year result, mean visual acuity was almost unchanged at $4.6 \pm 4.4$ in the right eye and $4.7 \pm$ 4.4 in the left eye. Six patients were blind in both eyes, secondary to RP/detachment or rubeotic glaucoma.

Analysing the data by best eye only, $84 \%$ of patients had vision of $6 / 12$ or better at the time of initial assessment, declining after 5 years to $81 \%$ and by 10 years to $80 \%$ (Table 6 ).

Disc and peripheral new vessels. There was a significant improvement in both disc and peripheral neovascularisation. After 5 years, disc new vessels in both eyes had improved from a mean of $2.7 \pm 1.6$ to $0.8 \pm 1.2(p<$ $0.001)$. By 10 years there was almost no evidence of neovascularisation in any eye (Fig. 3). The 19 patients who have reached the 15-year follow-up have no evidence of disc neovascularisation, though 4 still have evidence of peripheral new vessels. The improvement in neovascularisation was matched with a reduction in the incidence of vitreous haemorrhage. At 1 year, 14 $(14.4 \%)$ patients had one eye that was unassessable because of haemorrhage ( 2 being unassessable in either eye), while by 10 years only $4(8.5 \%)$ had this complication. There was a tendency for patients who had undergone photocoagulation in addition to pituitary ablation to lose neovascularisation more rapidly than those who had undergone pituitary ablation alone. For instance, at 5 years the mean grading of disc new vessels in the right eye in those who had photocoagulation had fallen from an initial grading of $2.7 \pm 1.9$ to $0.3 \pm$ 0.7 , whereas in those treated by pituitary ablation alone it had fallen from $2.7 \pm 1.4$ to $1.1 \pm 1.4$. By 10 years, there was no difference between the two groups.

Retinitis proliferans. The mean grading for RP increased from $1.0 \pm 1.3$ to $1.8 \pm 1.3$ at 10 years. The increase in RP does not mean that new vessels invariably progressed to RP, as some disc vessels resolved without residual fibrous tissue. In general, the more severe the neovascularisation at the initial assessment, the more likely RP was to develop. RP was the other major cause of eyes becoming unassessable.

Hard exudates, microaneurysms and haemorrhages. There was a significant reduction in the level of exudates from initial to ten years $(0.68 \pm 0.73$ versus
$0.15 \pm 0.28, p<0.001)$. Those who underwent photocoagulation after implant reduced their level of exudates more rapidly than those who underwent implantation alone. Thus, at 15 years grading in the right eye was $0.4 \pm 0.6$ in those who had not undergone photocoagulation but $0.1 \pm 0.2$ in those who had (NS).

Microaneurysms and haemorrhages declined significantly during the first year whether the patients had undergone photocoagulation or not $(2.3 \pm 1.1$ versus $1.3 \pm 0.7, p<0.01)$.

\section{Discussion}

The initial assessment of the proportion of patients thought to be completely ablated was probably accurate as assessed by contemporary methods, but with the passage of time may have become an underestimate. All patients studied who were thought to be completely ablated were confirmed to be so. In addition, two of those thought to be partially ablated were now found to have no residual pituitary function. This may have resulted from fibrosis of the pituitary gland. Those thought to be partially ablated had variable residual pituitary function. In all of these, GH production is disproportionately reduced compared with other pituitary modalities, in keeping with the findings of Shalet et al. [15], who found that irradiation of the hypothalamic-pituitary axis resulted in a greater reduction in GH than other pituitary hormones. If indeed $\mathrm{GH}$ is the important pituitary hormone in the pathogenesis of diabetic microvascular disease [16], then ${ }^{90} \mathrm{Y}$ implantation was theoretically successful in nearly all patients in whom the procedure was carried out.

In some situations, the combination of hypopituitarism and diabetes would appear to have an additive effect in terms of complications. Thus, hypotension can be aggravated by diabetic autonomic neuropathy; osteoporosis, which is reported to be more common in diabetic patients [17], has been a significant problem despite treatment with sex steroids. While most patients have managed to lead a normal life, the effects on the life of a sizeable minority have been devastating. Impotence and inability to produce children led to several episodes of depression requiring psychiatric help, and suicide in at least one case. Lethargy was a common complaint despite full replacement therapy. 


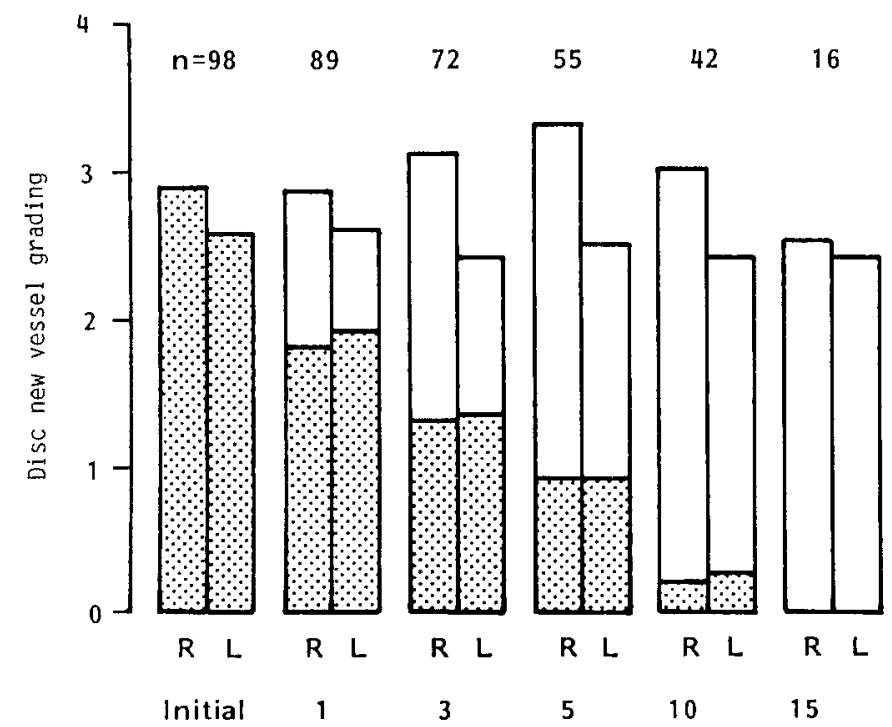

Fig. 3. Mean grading of new vessels with time in the 100 patients included in the ophthalmological follow-up. The shaded area represents the actual grading at that time point, and the open area the grading in that group of patients at the time of operation. The figures represent the number of patients included in each group

Interestingly, while men are happy to take replacement therapy with androgens, the women are reluctant to take oestrogens, despite a full explanation of the reasons for doing so. Fear of hypoglycaemia dominates the lives of many patients, and the advent of home blood glucose monitoring has been a help in this direction. Asymptomatic hypoglycaemia has become a major problem in the surviving patients, but is most likely due to long duration of diabetes and associated autonomic neuropathy rather than hypopituitarism, since lack of hypoglycaemic symptoms is also seen in nonablated diabetic subjects. It is surprising that there have been no episodes of ketoacidosis. It has, however, been previously reported [18] that hypopituitary diabetic patients are surprisingly slow to demonstrate a rise in plasma glucose and ketone bodies following insulin withdrawal, especially in association with steroid deficiency.

Mortality rates reported for patients with proliferative retinopathy vary. Two studies have reported figures of approximately $50 \%$ at 5 years $[19,20]$ and rather more among the diabetic blind [21]. A further study, selecting patients with 'a good prognosis for survival', reported a 5-year mortality of $25 \%$ amongst the patients with proliferative retinopathy [22]. Thus, the 5 -year mortality of $17.9 \%$ found in the present study is seen to be very low. This is presumably in part because the patients were a selected group with no significant evidence of renal dysfunction at the time of implant. A small clinical study of 51 patients with proliferative retinopathy who were selected to exclude patients with renal failure at the outset found a mortality rate of approximately $10-15 \%$ over a mean follow-up time of 6 years [23]. This seems to confirm that the low mortal- ity rate found in this study is largely due to the selection criteria. Nevertheless, the figure is still remarkably low when one considers that the combination of diabetes and hypopituitarism carries its own risks. Although the question is open to debate, it could be argued that those patients who died of hypoglycaemia died as a consequence of their hypopituitary state, as it is not common for diabetic patients to die of hypoglycaemia. In addition, there are a number of patients in whom clinical details suggest that they were admitted to hospitals where they were not known, and the dose of adrenal steroid was omitted or not increased to cover the intercurrent illness.

The large proportion of patients who died from myocardial or cerebral vascular disease is in keeping with the figures of other studies in diabetic patients [24, 25]. It is now accepted that diabetes predisposes to atheromatous disease. Pituitary ablation would be unlikely to have any effect on this.

The reports of Ireland et al. [26] and Greenwood et al. [27] of thinning of the glomerular basement membrane after pituitary destruction suggests that pituitary implantation may have beneficial effects on microvascular disease in kidney in the long-term, although there may have been early deterioration. Arriving at a figure indicating the numbers in this study who developed renal failure has been difficult. Taking all patients who had an elevated plasma urea is likely to be an overestimate, but including only those patients who developed renal failure secondary to diabetes is perhaps making too fine a point. However, in this group of 108 patients followed for a mean of 10 years, between 7 and 13\% developed renal failure. It is difficult to find data with which to compare this figure. In two large series from the Joslin Clinic looking at all diabetic patients [24] and those with proliferative retinopathy [28], some 50\% of patients of comparable age and duration of diabetes died of renal failure. In a study by Deckert et al. [29] of patients diagnosed as diabetic before the age of 31 years, $31 \%$ died of renal failure. Even in the small study of patients with proliferative retinopathy in whom patients with renal failure were excluded, $24 \%$ of patients died of or developed uraemia over the mean follow-up period of 6 years [23]. This is approximately double the figure found in the present report. However, a study examining the prognosis for renal function in otherwise fit patients with proliferative retinopathy is needed.

The fall in plasma creatinine with time following pituitary ablation reported by Lundbaek et al. [30] has not been confirmed. In addition, there was a pronounced rise in plasma urea at 6 months post implant which subsequently returned to normal. Although previously reported [31], the cause of this is not clear. Presumably by 6 months all patients had recovered from the acute effects of the procedure. Possible causes are a sudden fall in glomerular filtration rate, loss of muscle mass or possibly dehydration due to diabetes insipi- 
dus, which occurred in a number of patients as an early complication.

The ophthalmological results presented here are in accord with the findings of short-term assessments of pituitary ablation in the treatment of diabetic retinopathy $[10,32]$, confirming it as an effective method of treatment. To find suitable control series, it is necessary to examine the literature prior to the use of photocoagulation, as it is would now be considered unethical to withold this treatment in a patient with neovascularisation. The first important point to note is that spontaneous regression of untreated proliferative retinopathy is uncommon, being less than $10 \%$ in one early study [33]. Since the new vessels regressed in all patients in the present study, the benefit of pituitary ablation can be readily appreciated. In fact, as late as 1978 the results of pituitary ablation in the treatment of 'florid' retinopathy were being compared favourably with those of photocoagulation [11,34]. The benefit of pituitary ablation is also apparent on assessment of visual outcome. Three studies of untreated proliferative retinopathy put the progression to blindness at $27-50 \%$ $[23,29,35]$, whereas in the present study group the percentage of patients blind in both eyes remained at $12 \%$ from 3 to 15 years. The difference in visual acuity between the right and left eyes has been previously noted [36], and it has been postulated that this is due to differences in blood supply between the two eyes. In the analysis of this data the role of photocoagulation is a complicating factor, as it played an increasing part in treatment as the benefits of the xenon, and later the argon, photocoagulators became obvious. However, when photocoagulation was first introduced in 1970, the exact indications for its use were not clearly established, nor was the treatment given adequate in the light of later experience. The precise impact on the present results, therefore, is difficult to assess. For example, two patients had retinal detachment and blindness precipitated by xenon treatment, and some of the 15 patients in whom photocoagulation failed to cause regression of new vessels had inadequate treatment. Nevertheless, its influence cannot be ignored, since by the 10 -year follow-up more than $50 \%$ of the surviving 49 patients had received photocoagulation. The main influence seems to have been on the rapidity of resolution of neovascularisation. However, even if the photocoagulated group is removed from the analysis a significant improvement is still apparent in those who had undergone pituitary ablation alone. There was no difference in final visual acuity between the two groups. In conclusion, the present results indicate that destruction of the pituitary gland may have had a beneficial effect on the microvascular complications of diabetes.

Acknowledgements. We wish to acknowledge the contributions of Professors R. Fraser and F. Doyle, and the substantial contributions of Dr. N. Oakley, Dr. D. Scott, Professor D. Hill, Mr. R. Blach, Mr.
A.M. Hamilton and Mr. H. Cheng. This work was supported by the British Diabetic Association.

\section{References}

1. Poulsen JD (1953) Diabetes and anterior pituitary deficiency. Diabetes 2: 7-12

2. Luft R, Olivecrona H (1955) Hypophysectomy in man: further experience in severe diabetes mellitus. Br Med J 2: 752-56

3. FraserTR, Joplin GF, Lewis JW, Morrison R, Steiner RE (1959) Needle implantation of yttrium seeds for pituitary ablation in cases of secondary cancer. Lancet $1: 382$

4. Joplin GF, Hill DW, Scott DJ, Fraser TR (1962) Pituitary ablation in the treatment of diabetic retinopathy. In: Pyke DA (ed) Disorders of Carbohydrate Metabolism. Pitman, London Massachusetts, pp 207-212

5. Joplin GF, FraserTR, Hill DW, Oakley NW, Scott DJ, Doyle FH (1965) Pituitary ablation for diabetic retinopathy. Q J Med 34: 443-65

6. Joplin GF, Oakley NW, Hill DW, Kohner EM, FraserTR (1967) Diabetic retinopathy: comparison of disease remission induced by various degrees of pituitary ablation by Y-90. Diabetologia 3: 406-12

7. Oakley NW, Hill DW, Joplin GF, KohnerEM, FraserTR (1969) The treatment of diabetic retinopathy by pituitary implantation of radioactive yttrium. In: Goldberg MF, Fine SL (eds) Symposium on the treatment of diabetic retinopathy, Airlie House, Warrington, Virginia, Sept 29-Oct 1, 1968. US Government Printing Office, Washington DC, pp 317-29

8. KohnerEM, Dollery CT, FraserTR, BulpittCJ (1970) Effect of pituitary ablation on diabetic retinopathy studied by fluorescence angiography. Diabetes 19: 703-14

9. Panisset A, KohnerEM, Cheng H, FraserTR (1971) New vessels arising from the optic disc: response to pituitary implantation by yttrium-90 implant. Diabetes 20: 824-33

10. KohnerEM, Joplin GF, Blach RK, Cheng H, Fraser TR (1972) Pituitary ablation in the treatment of diabetic retinopathy: a randomised trial. Trans Ophthalmol Soc UK 92: 72-90

11. KohnerEM, Hamilton AM, Joplin GF, FraserTR (1976) Florid diabetic retinopathy and its response to treatment by photocoagulation or pituitary ablation. Diabetes 25: 1054-10

12. Harsoulis P, Marshall JC, Kuku SF, BurkeCW, London DR, Fraser TR (1973) Combined test for assessment of anterior pituitary function. Br Med J 4: 326-39

13. Oakley NW, Hill DW, Joplin GF, KohnerEM, FraserTR (1967) Diabetic retinopathy I: the assessment of severity and progress by comparison with a set of standard fundus photographs. Diabetologia $3: 402-5$

14. KohnerEM, Panisset A, Cheng H, FraserTR (1971) Diabetic retinopathy: new vessels arising from the optic disc: grading system and natural history. Diabetes 20: $816-23$

15. ShaletSM, BeardwellCG, MacFarlane IA, Morris Jones PH (1977) Endocrine morbidity in adults treated with cerebral irradiation for brain tumours during childhood. Acta Endocrinol 84: 673-80

16. Lundbaek K, Christensen NJ, Jensen VA, Johansen K, Olsen TS, Hansen AP, Orskov H, Osterby R (1970) Diabetes, diabetic angiopathy and growth hormone. Lancet 2: 131-33

17. Levin ME, Boisseau VC, Avioli LV (1976) Effects of diabetes mellitus on bone mass in juvenile and adult onset diabetes. $\mathrm{N}$ Engl J Med 294: 241-45

18. Barnes AJ, KohnerEM, Bloom SR, Johnston DG, Alberti KGMM, Smythe P (1978) Importance of pituitary hormones in the aetiology of diabetic ketoacidosis. Lancet 1: 1171-74

19. Caird FI (1969) Mortality in patients with diabetic retinopathy. In: CairdFI, Pirie A, Ramsell TG (eds) Diabetes and the eye. Blackwell, Oxford, pp 98-112

20. Davis MD, Hiller R, Magli YM (1979) Prognosis for life in patients with retinopathy: relation to severity of retinopathy. Trans Am Ophthalmol Soc 77: 144-70 
21. RogotE, GoldbergID, Goldstein H (1966) Survivorship and causes of death among the blind. J Chronic Dis 19: 179-97

22. KnatterudGL (1983) Mortality experience in the diabetic retinopathy study. Isr J Med Sci 19: 424-28

23. Deckert T, Simonsen E, Poulsen JE (1967) Prognosis for vision in proliferative retinopathy in juvenile diabetes. Diabetes 16: 728-33

24. Entmacher PS, Root HF, Marks HH (1964) Longevity of diabetic patients in recent years. Diabetes 13: 373-77

25. Keen H, Rose G, Pyke DA, Boyns D, Chlouverakis C, Mistry S (1965) Blood sugar and arterial disease. Lancet 2: 505-58

26. Ireland JT, PartnaikBK, Duncan JJP (1967) Effect of pituitary ablation on renal arteriolar and glomerular lesions in diabetes. Diabetes 25: 636-42

27. Greenwood RH, Ireland JT, Jones DJ, Mahler RF (1975) Diabetic complications in a patient with coexisting hypopituitarism. Diabetes 24: 1027-31

28. Root HF, MirskyS, Ditzel J (1959) Proliferative retinopathy in diabetes mellitus: a review of eight hundred and forty-seven cases. J Am Med Soc 169: 903-9

29. DeckertT, PoulsenJE, Larsen M (1978) Prognosis of diabetics with diabetes onset before the age of 31. Diabetologia 14:363-70

30. Lundbaek K, Malmros R, Andersen HC (1969) Hypophysectomy for diabetic retinopathy: a controlled clinical trial. In: Symposium on the treatment of diabetic retinopathy, Airlie House, Warrington, Virginia, Sept 29-Oct 1, 1968. Goldberg MF, Fine SL (eds) US Government Printing Office, Washington DC, pp 291-311

31. Teuscher A, Eschen F, Konig H, Zahnd T (1970) Long term effects trans-sphenoidal hypophysectomy on growth hormone, renal function and eyeground in patients with diabetic retinopathy. Diabetes 19: 502

32. Bradley RF, Rees SB, FagerSG (1965) Pituitary ablation in the treatment of diabetic retinopathy. Med Clin North Am 49: 1105-24

33. Beetham WP (1963) Visual prognosis of proliferating retinopathy. Br J Ophthalmol 47: 611-19

34. ValoneJA, McMeelJW (1978) Severe adolescent onset proliferative diabetic retinopathy: the effect of pituitary ablation. Arch Ophthalmol 96: 1349-53

35. CairdFI, Garret CJ (1963) Prognosis for vision in diabetic retinopathy. Diabetes 12: 389-97

36. Field RA, McMeel JW, Sweet WH, Schepens CL (1969) Hypophyseal stalk section for angiopathic diabetic retinopathy. In: Goldberg MF, Fine SL (eds) Symposium on the treatment of diabetic retinopathy, Airlie House, Warrington, Virginia, Sept 29-Oct 1. US Government Printing Office, Washington DC, pp 213-25

Received: 26 August 1986

and in revised form: 19 February 1987

Dr. E. M. Kohner

The Lower Medical Corridor

Hammersmith Hospital

Du Cane Road

London W12 OHS

UK 